\title{
Una nueva tésera de hospitalidad en territorio cántabro: el oso del castro de Las Rabas (Cervatos, Cantabria)
}

\section{A new tessera hospitalis in Cantabrian territory: the bear of the hillfort of Las Rabas (Cervatos, Cantabria)}

\author{
Pedro Ángel Fernández Vega \\ Rafael Bolado del Castillo
}

\begin{abstract}
RESUMEN
Presentamos una nueva tésera de hospitalidad procedente del castro de Las Rabas (Cervatos, Cantabria). Anepígrafa y con forma de piel de oso extendida, su hallazgo refuerza la existencia del hospitium dentro del pueblo cántabro así como el mantenimiento de unas fluidas relaciones con la Meseta y la Celtiberia, en donde encontramos su paralelo más cercano.
\end{abstract}

\section{SUMMARY}

We present a new tessera hospitalis from the hillfort of Las Rabas (Cervatos, Cantabria). Anepigraphic and with extended bearskin form, its finding reinforces the existence of hospitium among the Cantabrian people and the maintaining of fluid relations with the Plateau and Celtiberia, where we find its closest parallel.

PALABRAS CLAVE: tésera, hospitalidad, hospitium, cántabros, Edad del Hierro.

KEY WORDS: tessera, hospitality, hospitium, Cantabrian, Iron Age.

\section{INTRODUCCIÓN}

Para infortunio de la Arqueología y de la Historia, la Edad del Hierro en Cantabria, entendida y comprendida desde la visión de la Cantabria Antigua, siempre ha llamado la atención más por el desconocimiento que de ella teníamos que por las certezas arqueológicamente contrastadas. No obstante, desde la década de los ochenta del siglo pasado, la voluntad y el esfuerzo de los distintos grupos de investigadores ha permitido aportar un poco de luz a un panorama de por sí desalentador. Excavaciones como las realizadas en los castros de los Baraones (Valde- gama, Palencia), Argüeso-Fontibre (Hermandad de Campoo de Suso, Cantabria), Monte Bernorio (Villarén, Palencia), Castilnegro (Liérganes-Medio de $\mathrm{Cu}$ deyo, Cantabria), la Espina del Gallego (Corvera de Toranzo-Arenas de Iguña, Cantabria), el Alto de la Garma (Omoño, Cantabria), la Ulaña (Humada, Burgos), Peña Amaya (Amaya, Burgos), Las Rabas (Cervatos, Cantabria) o Santa Marina-Monte Ornedo (Valdeolea, Cantabria), nos llevan a conocer a un pueblo alejado de los tópicos asumidos en el ideario popular, así como de la mediática imagen de fieros y aguerridos montañeses protagonistas de las continuas hostilidades que sufrían sus vecinos. Nos encontramos ante gentes de honda raíz indoeuropea que habitan en poblados fortificados con cabañas de planta circular o de tendencia rectangular, cuya economía se basa fundamentalmente en la ganadería, en la práctica de una agricultura extensiva y en el aprovechamiento de los aportes que pueden recibir de actividades complementarias como la caza, la pesca, la recolección o los intercambios comerciales. Una sociedad que, para poder existir, debió asentarse y apoyarse sobre una organización sociopolítica compleja que velase en todo momento por su buen funcionamiento, no solamente intramuros, para con sus habitantes, sino también extramuros, donde los lazos con las tribus y pueblos vecinos, o con intereses comunes en tierras lejanas, no sólo constituirán un símbolo de prestigio, sino la garantía de su desarrollo.

En este sentido las tesserae celtibéricas parecen alzarse como evidencias materiales de la existencia de pactos entre las distintas comunidades indígenas. Acuerdos de diversa índole y magnitud que, como 
prueba el ejemplar que presentamos, el primero hallado en Cantabria y en territorio cántabro, en el marco de un programa de actuaciones arqueológicas dirigido desde el Museo de Prehistoria y Arqueología de Cantabria con el apoyo de la Consejería de Cultura, Turismo y Deporte del Gobierno de Cantabria, no fueron ajenos a este pueblo en el que, desde el siglo III a.C., ya se hacen notar las relaciones comerciales con los núcleos de la Meseta.

\section{EL HALLAZGO}

En 2009, inmerso en un proyecto de mayor amplitud que intenta dar forma a la creación de un parque arqueológico en las comarcas de Campoo de Enmedio y Valdeolea (Cantabria), se retomaron los trabajos arqueológicos en el castro de Las Rabas (Cervatos) (Fig. 1); uno de los yacimientos de la Edad del Hierro que más bagaje científico ha tenido en nuestra región y que más dudas e interrogantes nos plantea.

Descubierto en la segunda mitad del siglo xx (García Guinea y Rincón 1970: 9; García Guinea 1997: 25), las primeras excavaciones vinieron de la mano del equipo de Miguel Ángel García Guinea en los años 1968-1969 (García Guinea y Rincón 1970) siendo continuadas por Vega et al. (1986) diecisiete años después. De sus resultados y las distintas inter- pretaciones existentes podemos colegir que se trata de un poblado de una extensión de unas diez hectáreas, con un sistema de defensa a base de murallas de piedra con sillares trabajados, adscribible a los siglos IV/III-I a.C. Si albergó o no un entramado urbano aún lo desconocemos pues, a pesar de las noticias sobre la existencia de cabañas de planta circular, las pruebas que lo contrastan son mínimas, quedando relegadas a varios fragmentos de conglomerados de pared, uno de ellos con decoración de círculos impresos a modo de cenefa (Vega et al. 1986; García Guinea 1997: 26; 1999: 104; Bolado del Castillo et al. en prensa; Bolado del Castillo y Fernández Vega 2010: 411-412). No obstante, sí estamos en condiciones de afirmar que nos encontramos ante un núcleo de población relevante dentro de la Edad del Hierro de la comarca de Campoo. Su posición estratégica, económicamente hablando, y la abundancia y variabilidad tipológica de los restos materiales hallados, así parecen demostrarlo.

Las tres campañas realizadas, aunque cortas, han permitido esbozar un rápido boceto de lo que fue un poblado dedicado a la ganadería y agricultura, complementadas siempre por las actividades cinegéticas y silvicultoras, que paulatinamente abrió su horizonte hacia las influencias provenientes de la Meseta. El mejor ejemplo lo podemos ver en la cerámica, en donde claramente se distinguen dos grandes produc-

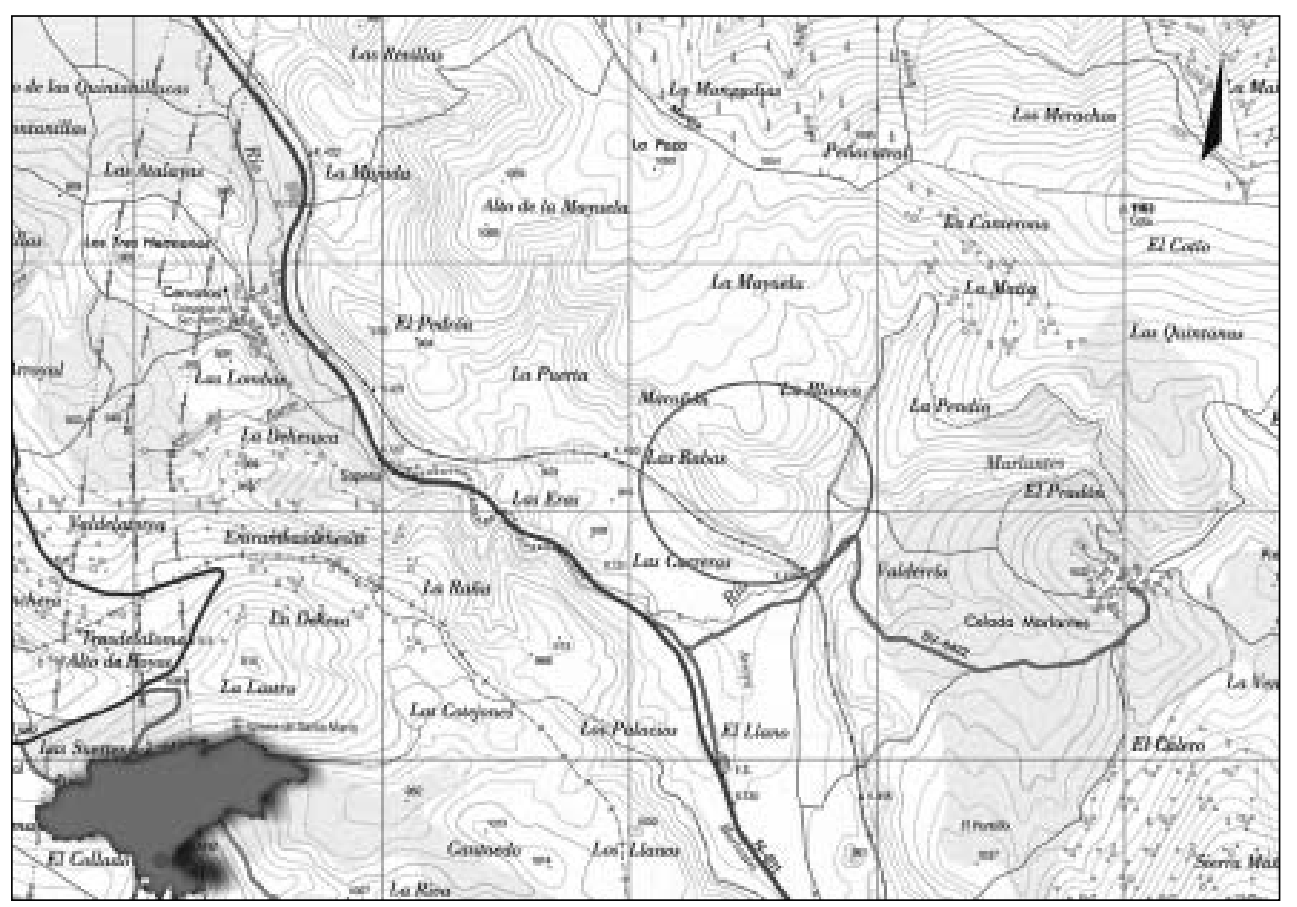

Figura 1. Localización sobre mapa topográfico del castro de Las Rabas (Cervatos, Cantabria). 
ciones: la propiamente prerromana, caracterizada por sus pastas poco decantadas trabajadas en su mayoría a mano, cocción en ambiente reductor y decoraciones a base de incisiones en zig-zag, puntillados, mamelones, acanaladuras, ungulaciones en cuerpo y labio, estampillados triangulares y de cazoletas, peinados o bruñidos; y una producción torneada, de pastas decantadas y cocción oxidante que, en algunas ocasiones, conserva una decoración pintada con tintes negruzcos que dan forma a motivos geométricos (círculos y líneas) o, en los casos más complejos, a escenas con animales, vegetación o símbolos solares como la esvástica; es decir, la denominada cerámica celtibérica. Analizando ambas producciones, lo primero que nos llama la atención es una representatividad diferencial dentro del registro arqueológico del yacimiento. Del total, más de un $90 \%$ se corresponde con la cerámica prerromana, mientras que en el restante $10 \%$ se incluirían las piezas celtibéricas y algunos fragmentos polémicos de cerámica campaniense (García Guinea y Rincón 1970; Marcos García 1985; 1987; 1988; 1989; Aja et al. 1999: 37-39; Bolado del Castillo y Fernández Vega 2010: 412-420). ¿Qué nos indica esto? Las cifras creemos que hablan por sí solas, los pobladores de Las Rabas se aprovisionarán mayoritariamente de una cerámica producida localmente mientras que el pequeño índice de cerámica celtibérica nos advierte de una manufactura alóctona que llega durante el denominado proceso de celtiberización.

Materiales como los denarios celtibéricos (tres ejemplares de Turiaso y uno de Śekobirikes), una cuenta oculada, un fragmento de torque, placas articuladas con profusa decoración o una grapa de rienda de caballo con decoración laminar apoyan más si cabe la existencia de este período aperturista que, gracias a la pieza objeto de este artículo, podemos plantear razonablemente que pasó de lo meramente comercial, centrado en el intercambio de mercancías, al establecimiento de relaciones socioeconómicas o, por qué no, sociopolíticas de mayor solidez.

Con la llegada de Roma llegó también el ocaso de la ocupación de Las Rabas, un final que, cada vez más, parece haber adquirido tintes violentos. Ya desde las primeras intervenciones el equipo dirigido por García Guinea parecía intuirlo, tornándose en una realidad un poco más afianzada con el descubrimiento y excavación de los cercanos campamentos romanos de La Poza (Campoo de Enmedio) (Cepeda 2006; 2007; 2008. Cepeda et al. 2009) y con la identificación de las primeras posibles piezas de militaria romana (Fernández Ibáñez 1999: 254; 2006: 260-261; 2007: 404), que finalmente hemos podido certificar (Bolado del Castillo y Fernández Vega 2010: 422;
Bolado del Castillo et al. en prensa). Los puntos marcados sobre el mapa nos dibujaban un claro escenario militar, aunque cubierto aún por una suave neblina que, a pesar del descubrimiento de un nuevo castellum en El Pedrón (Cervatos), ubicado a escasos 1,5 km del castro, seguía sin disiparse. Teníamos dos de los agentes claves para identificar un conflicto: un asaltante (el primer campamento de La Poza auxiliado por El Pedrón) y un asaltado (Las Rabas), pero carecíamos del hilo conductor que los relacionase, de unas pruebas materiales propias de un episodio de incendio y destrucción.

Conociendo las pautas de comportamiento del ejército romano durante las Guerras Cántabras, y con el objetivo de aportar un poco de luz al ocaso de Las Rabas, se decidió llevar a cabo en 2009 una prospección magnética intensiva, por el área extramuros, a la búsqueda de las evidencias del asalto y del sector por el que tuvo lugar. Aunque sea el objeto de otro artículo, podemos avanzar que los resultados fueron más positivos de lo esperado, tanto que, para nuestra sorpresa, en las coordenadas Huso 30 X-408.605 Y4.755.935, hizo su aparición esta pequeña tésera con forma de piel de oso extendida. A falta de un inminente sondeo que lo ratifique, la pieza no parece estar asociada a nivel arqueológico alguno. La tierra removida, tanto en el punto exacto como en las cercanías, no aportó nada, lo que nos hace pensar que, junto al fragmento de cuchillo de las coordenadas Huso $30 \mathrm{X}$ 408.606 Y-4.755.934, procedan del aterrazamiento agrícola situado 2-3 $\mathrm{m}$ al norte y sobreelevado entorno a $1 \mathrm{~m}$ respecto al lugar de hallazgo (Fig. 2).

\section{LA TÉSERA DE OSO DE LAS RABAS}

Se trata de una pequeña pieza de bronce de pátina de color verde oliva, realizada mediante la técnica de la cera perdida, que presenta unas dimensiones de $4,9 \times 3,8 \times 0,5 \mathrm{~cm}$ y un peso de 25,2 gr. En su anverso (la cara donde emerge el volumen figurativo), se aprecia la representación de un oso desde una perspectiva cenital cuya superficie es decorada por líneas incisas paralelas en el cuello, hocico y en los extremos de las patas, delimitando unas pezuñas que aparecen remarcadas por un rebaje semicircular con incisiones a modo de garras. El reverso, por su parte, es completamente liso y plano, acogiendo un total de seis agujeros (uno en cada extremo de las patas y tres en el cuerpo), posibles hembras de unión para confrontar y encajar una pieza hermana, como la tésera conservada en la Real Academia de la Historia que, por otro lado, constituye nuestro paralelo más cercano y gracias al 


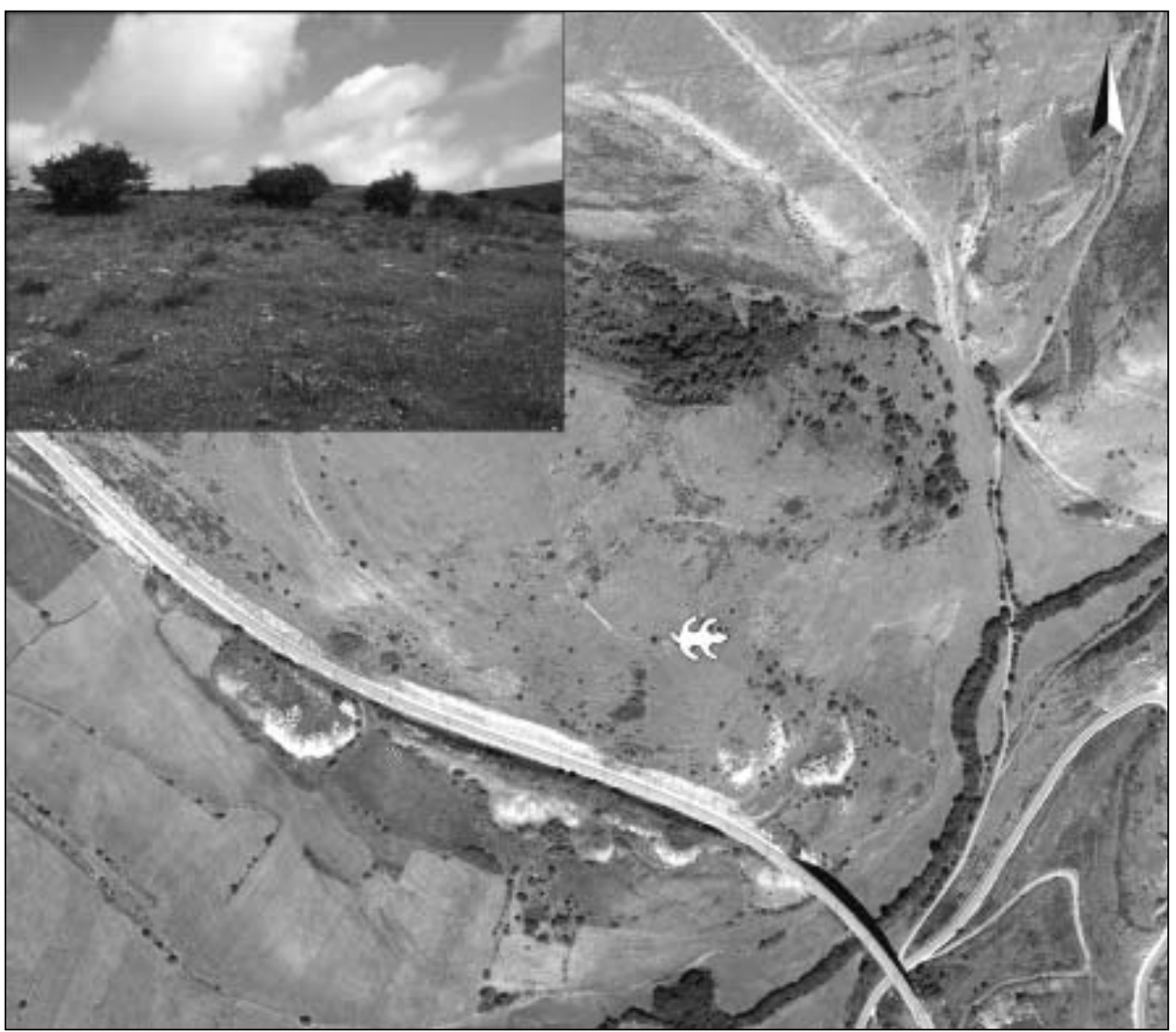

Figura 2. Lugar de hallazgo de la tésera de oso del castro de Las Rabas.

cual no existe duda alguna de que nos encontremos ante una tésera de hospitalidad (Figs. 3 y 4).

De procedencia desconocida, el ejemplar de la R.A.H. presenta una representación cenital idéntica, unas dimensiones muy similares $(4,8 \times 3,8 \times 0,7 \mathrm{~cm})$ y un peso de 32 gr (Gómez Moreno 1949: 311, n.․ 87; Almagro Basch 1982: 201-202, 207-208; 1984: 15-17; Lorrio 1997: fig. 138.1, lam. VII, 3; Untermann 1997: 542-544, n. ${ }^{\circ}$ K.0.4; Almagro-Gorbea 2001: 277; Alma-

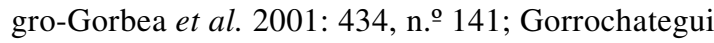
2001: 205; Almagro-Gorbea 2003: 218-219; 2004: 293, 340-341; Jordán 2004: 240; Jimeno 2005: n. . $^{-}$ 260). Su anverso, como podemos ver en las figuras y en las numerosas fotos publicadas, recuerda inmediatamente a la pieza cántabra diferenciándose por leves matices como pueden ser la interrupción de las líneas incisas en las patas posteriores o el morro menos anguloso. El reverso, plano, ofrece siete remaches cuyo fin sería servir de acople a una pieza hembra como la de Las Rabas. Entre ellos, hacia la pata delantera derecha, se dispone la inscripción celtibérica libiaka, un adjetivo derivado del nombre de población de Libia en el que Almagro Basch (1984: 16-17) ve a la Libiana de Ptolomeo (2.6.57), situada en el territorio de Segobriga, pero que autores como Tovar (1948: 79-80) o Untermann (Untermann 1997: 542, n. K.0.4.) relacionan con la riojana Libia de los Berones y los Libienses, citada por Plinio (3.24) y recogida en el Itinerario de Antonino (394.2).

Dentro de los cuatro grandes grupos en que se dividen las téseras - anepígrafas, epígrafas con lengua y escritura celtibérica, epígrafas con escritura latina y lengua celtibérica, y epígrafas con escritura y lengua latinas (Abascal 2002: 24; Torija y Baquedano 2007: 286, 297)—, nuestro ejemplar, como es obvio, debe incluirse en el primero de ellos. Aunque cuantitativamente menor, el corpus de téseras sin inscripción no deja de ser relevante, destacando en él piezas como las téseras procedentes de El Escorial (Madrid) (Almagro-Gorbea 2004: n.o 613. N. 613a), la cabeza, el toro y los ejemplares geométricos de La Custodia (Navarra) (Labeaga y Untermann 1993-1994: 47 48; Labeaga 1999-2000: 161-162; Almagro-Gorbea 2004: 616); el caballo, el pez y la pieza rectangular con escotaduras de Sasamón (Burgos) (Torija y Baquedano 2007: 278-281); las téseras de Alcácer do Sal 


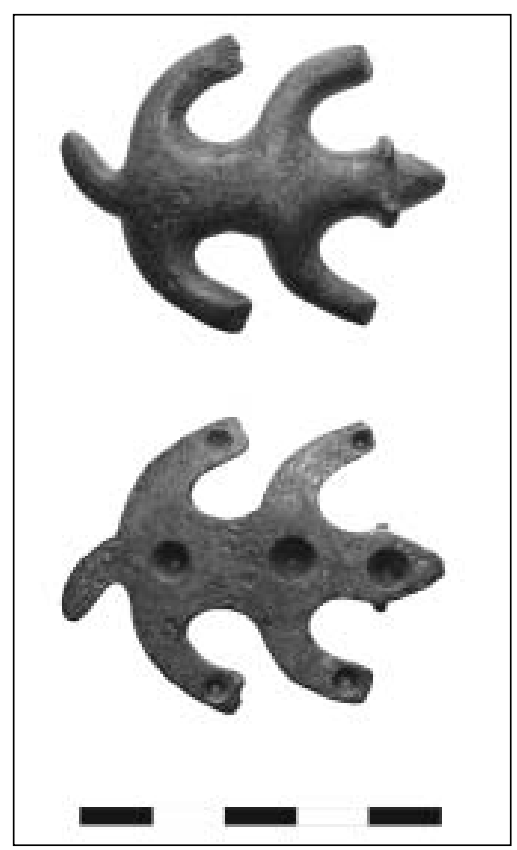

Figura 3. Fotografía de la tésera de oso del castro Las Rabas.

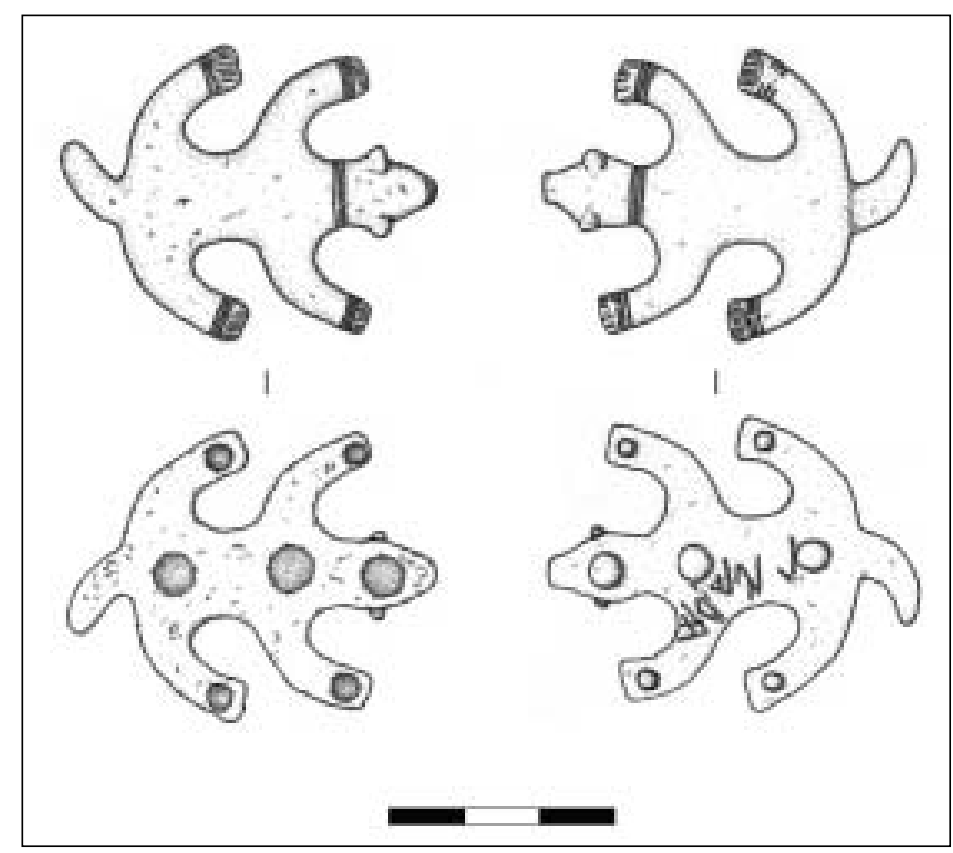

Figura 4. Dibujo de la tésera de oso del castro de Las Rabas (izquierda) y la tésera de oso conservada en la Real Academia de la Historia (derecha) (Dib. Rafael Bolado del Castillo).
(Alentejo, Portugal) (Pérez 1999: 501); la cabeza de toro de Villasviejas de Tamuja (Cáceres) (AlmagroGorbea 2004: n.․ 602); las piezas con forma de cabeza, cabeza lobuna, piña o capullo, cubo, bicónica y abstracta de procedencia desconocida y conservadas en la Real Academia de la Historia (Almagro-Gorbea 2004: n.o 685, 687, 694, 695, 697 y 698); las cabezas de diversas procedencias recogidas por AlmagroGorbea (2004: 303) o el supuesto perro de Ávila que parece tener su pareja en una tésera epígrafa de similares características conservada en el Museo Arqueológico Nacional (Almagro Gorbea y Turiel 2003: 376377; Almagro-Gorbea 2004: n.․ 594). De Villaricos parece proceder también lo que ha sido identificado como una tésera anepígrafa que, en este caso, fue realizada sobre material óseo (Fernández Mastro 1991: 453). La ausencia de inscripción se justifica y se enmarca en una sociedad, hasta donde se intuye o conoce, iletrada, que debió dar mayor importancia a la forma y símbolo de la tésera con la que se sellaba el acuerdo, que a la presencia de una formula ininteligible para uno o ambos contrayentes (Almagro-Gorbea 2004: 305; Ramírez 2005: 281).

La representación tanto de la tésera de Las Rabas como de su paralelo destaca sobre todo por su singularidad. Un simple vistazo a los motivos de las téseras zoomorfas hispanas o a la iconografía y re- presentaciones animalísticas más habituales, nos mostrará cómo los convencionalismos artísticos dan forma a las figuras de perfil, no desde el aire, por lo que la selección de su perspectiva, al igual que la forma de oso, no fue algo aleatorio. Ejemplos de animales representados desde una perspectiva cenital los encontramos recogidos en trabajos como los de Romero y Sanz (1992), Blanco García (1997) o Abarquero Moras (2006-2007), destacando piezas como el vaso del poblado de Azaila (Cabré 1944: 68, fig. 55, lam. 33.2), la tapadera para el horno de Pintia (Sanz y Velasco 2003: 79), el vaso de los lobos procedente de Eras de San Blas (Burgos) (Abarquero 2006-2007: 188-193), las vasijas de Cauca (Blanco 1998: 185-187), las cerámicas con decoración plástica de Eras del Bosque (Palencia) (Taracena 1947: 90-91, lam. XXIX. Carretero y Guerrero 1990: 373374, 381.), algunas fíbulas/colgantes (Álvarez 1941: 160-161, lam. CLXIV; Jimeno 2005: n.o 128), la famosa representación del Cernnunos numantino (Romero 1973: 37-50. 1976a: 24; 155-158 y 161; 1976b: 383-385; Alfayé 2003: 77-79) o el cánido de caldero de Gundestrup (Dinamarca).

Su significado, más allá de una genérica caracterización mágico-religiosa, es difícil de precisar, existiendo posiblemente innumerables particularismos en función del objeto o figura representados. No sería 
extraño, por tanto, ver en ellos a dioses, seres mágicos, mitológicos y sagrados, formando parte de escenas del imaginario religioso y popular o, simplemente, cumpliendo una función apotropaica, protegiendo los productos de sus contenedores, los hornos, o a sus poseedores (Blanco 1997: 197-198; Abarquero 2006-2007: 199-204). En nuestro caso, creemos que el oso debe ser puesto en relación con la divinidad garante del pacto de hospitalidad. Parece más improbable la posibilidad de que se trate de la representación del animal sacrificado para ratificar el acuerdo, pues, aunque es asumible esta interpretación para otros ejemplares de téseras, la caza, captura y sacrificio de un oso se antoja difícil. Esta misma propuesta podría plantearse para la tésera de Arcobriga (Monreal de Ariza, Zaragoza) en la cual Jordán ve un oso (2004: 242), mientras otros autores identifican la representación de un buey o toro mayor (Torija y Baquedano 2007: 274-275, 292). Existe una tercera posibilidad a tener en cuenta: que nos encontremos ante el símbolo de un núcleo de población estrechamente relacionado con los osos y lo que representan, el cual sería el promotor del pacto.

En cuanto a su cronología, como veíamos, aunque se trata de una pieza hallada en el marco de una intervención arqueológica, carece de un contexto preciso. No obstante somos partidarios de seguir la propuesta del ejemplar de la Real Academia de la Historia, fechado entre los siglo II-I a.C., coincidiendo con el período de mayor auge de este castro y, posiblemente, del resto de poblados cántabros ubicados en los límites meridionales.

\section{CONCLUSIONES}

El ejemplar de Las Rabas pasa a formar parte del pequeño corpus de téseras halladas en territorio cántabro, en donde se integran la pieza de manos entrelazadas de Monte Cildá (Olleros de Pisuerga, Palencia), fechada en el siglo I a. C. (Peralta 1993: 223-226; 2003: 143-145), y otro reciente ejemplar con forma de cabeza de carnero y texto en celtibérico, hallado en El Otero (Colmenares de Ojeda y Cantoral de la Peña, Palencia), del que tenemos noticias gracias a Eduardo Peralta Labrador (en prensa). Las tres téseras nos permiten constatar materialmente la existencia de pactos de hospitalidad entre los cántabros en los siglos II-I a.C., coincidiendo con un momento en el que los lazos y relaciones con los núcleos de los valles del Duero y del Ebro se dinamizan y desarrollan. Al menos así parece entreverse en el registro material de los pocos castros excavados hasta el momento, ya que, a partir del siglo III a.C., junto a los tradiciona- les objetos autóctonos se documentan materiales alóctonos como las cerámicas celtibéricas, las fíbulas de caballito o los denarios celtibéricos. Estos hallazgos se explicarían convencionalmente por la inmersión de los cántabros en la órbita de influencia celtíbera desde una perspectiva difusionista que parte de un mejor conocimiento de la realidad material alóctona.

La finalidad última que motivó la fabricación de estos bronces seguirá permaneciendo oculta. Cualquiera de las propuestas existentes hasta el momento pueden darse por buenas: hospitium, derechos de paso, concesiones de ciudadanía, actividades relacionadas con la trashumancia... Por lo que respecta a las partes contrayentes quizá dispongamos de algo más de información: según Peralta, la tésera de cabeza de carnero hace directa alusión a una ciudad mientras que, en la procedente de Monte Cildá, puede leerse con claridad la referencia a la ciudad de $T u$ riaso, una población ampliamente representada dentro del numerario celtibérico recuperado de territorio cántabro. En cuanto a la tésera de Las Rabas, aunque anepígrafa, no deberíamos descartar a priori que pudiera relacionarse con la otra pieza análoga, de posible procedencia conquense.

No nos cabe duda de que piezas como las referidas ponen en evidencia la existencia, entre los cántabros de la Segunda Edad del Hierro, de una organización sociopolítica y económica compleja que poco a poco se va desvelando. Lejos de cualquier duda, como las suscitadas para la tésera de Monte Cildá (Beltrán et al 2009: 654), el ejemplar presentado se vincula directamente con el castro de Las Rabas, desenmascarando, gracias a los esfuerzos de las sucesivas intervenciones, un asentamiento clave para el avance, comprensión y desmitificación del supuesto cariz retardatario o culturalmente pobre de la Edad del Hierro en Cantabria. La arqueología de los antiguos cántabros comienza a desmentir el barniz de barbarie y salvajismo que tradicionalmente envuelve a este pueblo y que tiene su origen en la visión de Estrabón, claramente comprometida con la versión romana de lo ocurrido durante las Guerras Cántabras.

\section{BIBLIOGRAFÍA}

Abarquero Moras, F. J. 2006-2007: «Simbolismo cenital en el mundo vacceo a propósito de un recipiente de cerámica de las Eras de San Blas (Roa, Burgos)». Boletín del Seminario de Estudios de Arte y Arqueología LXXII-LXXIII: 183-209.

Abascal Palazón, J. M. 2002: «Téseras y monedas. Iconografía zoomorfa y formas jurídicas de la Celtiberia». Paleohispanica 2: 9-35. 
Aja, J. R.; Cisneros Cunchillos, M. A.; Diez Castillo, A. y López Noriega, P. 1999: El poblamiento de montaña en el sector central de la Cordillera Cantábrica. Fuentes escritas y arqueológicas. El ejemplo de la comarca de la Braña (Palencia). BAR International Series 759. Oxford.

Alfayé Villa, S. 2003: «La iconografía divina en la Celtiberia: una revisión crítica». Archivo Español de Arqueología 76: 77-96.

Almagro Basch, M. 1982: «Tres téseras celtibéricas de bronce de la región de Segóbriga, Saelices (Cuenca)». Homenaje a Conchita Fernández Chicarro, Directora del Museo Arqueológico de Sevilla. Ministerio de Cultura. Madrid: 195-210.

Almagro Basch, M. 1983: Segobriga I. Los textos de la Antigüedad sobre Segobriga y las discusiones acerca de la situación geográfica de la aquella ciudad. Excavaciones Arqueológicas en España 123. Madrid.

Almagro Basch, M. 1984: Segobriga II. Inscripciones ibéricas, latinas paganas y latinas cristianas. Excavaciones Arqueológicas en España 127. Madrid.

Almagro-Gorbea, M. 2001: «Tésera de bronce en forma de piel de oso extendida». En M. AlmagroGorbea (ed.): Tesoros de la Real Academia de la Historia. Madrid: 277.

Almagro-Gorbea, M. 2003: Epigrafía Prerromana. Real Academia de la Historia, Gabinete de Antigüedades. Madrid.

Almagro-Gorbea, M. (ed.) 2004: Prehistoria. Antigüedades Españolas I. Real Academia de la Historia. Madrid.

Almagro-Gorbea, M. y Turiel Ibáñez, M. 2003: «Adquisiciones recientes. Colección Turiel». En M. Almagro-Gorbea: Epigrafía Prerromana. Real Academia de la Historia, Gabinete de Antigüedades. Madrid: 369-379.

Almagro-Gorbea, M.; Mariné, M. y Álvarez Sanchís, J. R. (eds.) 2001: Celtas y Vettones. Institución Gran Duque de Alba y Real Academia de la Historia.

Álvarez Ossorio, F. 1941: Catálogo de los exvotos de de bronce ibéricos del Museo Arqueológico $\mathrm{Na}$ cional. Madrid.

Beltrán Lloris, F.; Jordán Cólera, C. y Simón Cornago, I. 2009: «Revisión y balance del corpus de téseras celtibéricas». Palaeohispanica 9: 625-668.

Blanco García, J. F. 1997: «Zoomorfos celtibéricos en perspectiva cenital. A propósito de los hallazgos de Cauca y el Castro «Cuesta del Mercado» (Coca, Segovia)». Complutum 8: 183-203.

Bolado del Castillo, R. y Fernández Vega, P. A. 2010: Castro de Las Rabas (Cervatos, Campoo de En- medio). Castros y castra en Cantabria. Fortificaciones desde los orígenes de la Edad del Hierro a las guerras con Roma. Catálogo, revisión y puesta al día. ACANTO y Gobierno de Cantabria, Consejería de Cultura, Turismo y Deporte: Santander: 403-428.

Bolado del Castillo, R.; Fernández Vega, P. A.; Callejo Gómez, J. en prensa: «El recinto fortificado de El Pedrón (Cervatos, Cantabria), los campamentos de La Poza (Campoo de Enmedio, Cantabria) y el castro de Las Rabas: un nuevo escenario de las Guerras Cántabras». Kobie.

Cabré, J. 1944: Corpus Vasorum Hispanorum. Cerámica de Azaila. Madrid.

Carretero Vaquero, S. y Guerrero Arroyo, J. 1990: «La necrópolis romana de Eras del Bosque (Palencia). Materiales cerámicos». Actas del II Congreso de Historia de Palencia (Palencia 1989), tomo I. Diputación Provincial de Palencia. Palencia: 367-381.

Cepeda Ocampo, J. J. 2006: «Los campamentos romanos de La Poza (Cantabria)». En A. Morillo Cerdán (ed.). Arqueología Militar Romana en Hispania II: producción y abastecimiento en el ámbito militar. Universidad de León. León: 683-690.

Cepeda Ocampo, J. J. 2007: «La Poza». En A. Morillo Cerdán (ed.): El ejército romano en Hispania. Guía Arqueológica. Universidad de León. León: 373-375.

Cepeda Ocampo, J. J. 2008: «Prospecciones y sondeos arqueológicos en el yacimiento de La Poza (Campoo de Enmedio). Campaña de 2003». En R. Ontañón Peredo (coord.) Actuaciones Arqueológicas en Cantabria 2000-2003. Consejería de Cultura, Turismo y Deporte, Gobierno de Cantabria: 141144.

Cepeda Ocampo, J. J.; Iglesias Gil, J. M.; Ruiz Gutiérrez, A. y Sarabia Rogina, P. 2009: «La ciudad de Iuliobriga y los campamentos romanos de La Poza (Cantabria)». En A. Morillo, N. Hanel, y E. Martín (eds.): Limes XX. Estudios sobre la frontera romana. Roman frontier studies. Anejos de Gladius 13. Madrid: 631-638.

Fernández Ibáñez, C. 1999: «Metalistería y romanización en la Antigua Cantabria». Regio Cantabrorum. Santander: 249-258.

Fernández Ibáñez, C. 2006: «Post vestigium exercitus. Militaria romana en la región septentrional de la Península Ibérica durante la época altoimperial». En A. Morillo Cerdán (ed.). Arqueología Militar Romana en Hispania II: producción y abastecimiento en el ámbito militar. Universidad de León. León: 257-308.

Fernández Ibáñez, C. 2007: «La metalistería militar en 
Hispania en época Altoimperial». Sautuola, XIII. Metalistería de la Hispania Romana: 403-425.

Fernández Mastro, P. 1991: «La morfología de las téseras latinas de la Península Ibérica». XX Congreso Nacional de Arqueología (Santander 1989), Zaragoza: 453-456.

García Guinea, M.A. 1997: «El asentamiento cántabro de Celada Marlantes y la futura arqueología de los cántabros». Cuadernos de Campoo 7: 24-29.

García Guinea, M. A. 1999: «Significado de la excavación arqueológica en el castro de Las Rabas (Celada Marlantes)». Regio Cantabrorum. Santander: 99-106.

García Guinea, M. A. y Rincón, R. 1970: El asentamiento cántabro de Celada Marlantes. Instituto de Prehistoria y Arqueología «Sautuola». Diputación Provincial de Santander.

Gómez Moreno, M. 1949: Misceláneas. HistoriaArte-Arqueología. Madrid.

Lorrio, A.J. 1997: Los Celtíberos. Complutum Extra 7. Universidad de Alicante y Universidad Complutense de Madrid. Madrid.

Gorrochategui, J. 2001: «La lengua celtibérica». En M. Almagro-Gorbea, M. Mariné y J. R. Álvarez Sanchís (eds.): Celtas y Vettones. Institución Gran Duque de Alba y Real Academia de la Historia. Ávila: 201-208.

Jimeno Martínez, A. (ed.) 2005: Celtíberos. Tras la estela de Numancia. Diputación Provincial de Soria.

Jordán, C. 2004: Celtibérico. Universidad de Zaragoza. Zaragoza.

Labeaga Mendiola, J.C. 1999-2000: La Custodia, Viana, Vareia de los Berones. Trabajos de Arqueología Navarra 14. Institución Príncipe de Viana, Pamplona.

Labeaga Mendiola, J. C. y Untermann, J. 1993-1994: «Las téseras del poblado prerromano de La Custodia, Viana (Navarra). Descripción, epigrafía y lingüística». Trabajos de Arqueología Navarra 11: 4553.

Marcos García, M. A. 1985: Revisión y estudio de los materiales arqueológicos del yacimiento de Celada Marlantes conservados en el Museo Regional de Prehistoria y Arqueología. Universidad de Cantabria.

Macos García, M. A. 1987-1988-1989: «La cerámica como fuente para el conocimiento histórico etnográfico de Cantabria en la Antigüedad». Publicaciones del Instituto de Etnografía y Folklore «Hoyos Sainz», Vol. XIII: 235-244.
Peralta Labrador, E. 1993: «La tésera cántabra de Monte Cildá (Olleros de Pisuerga, Palencia)». Complutum 4: 223-226.

Peralta Labrador, E. 2003: Los Cántabros antes de Roma. Real Academia de la Historia. Madrid.

Peralta Labrador, E. en prensa: «Una nueva tésera de hospitalidad prerromana del territorio de los cántabros: La tésera de El Otero (Colmenares de Ojeda y Cantoral de la Peña, Palencia)».

Pérez Vilatela, L. 1999: «Celtíberos ricos en un país pobre». En F. Burillo (coord.): IV Simposio sobre los celtíberos. Economía (Daroca 1997). Institución Fernando el Católico: 497-502.

Ramírez Sánchez, M.E. 2005: «Clientela, hospitium y devotio». En A. Jimeno: Celtíberos. Tras la estela de Numancia. Soria: 279-284.

Romero Carnicero, F. 1973: «Nuevas aportaciones al estudio de la cerámica numantina». Celtiberia 45 : 37-50.

Romero Carnicero, F. 1976a: Las cerámicas polícromas de Numancia. Valladolid.

Romero Carnicero, F. 1976b: «Notas de cronología cerámica numantina». Boletín del Seminario de Estudios de Arte y Arqueología XLII: 377-392.

Romero, F. y Sanz, C. 1992: «Representaciones zoomorfas prerromanas en perspectiva cenital. Iconografía, cronología y dispersión geográfica». II Simposium de Arqueología Soriana (Soria 1989), tomo I. Soria: 453-471.

Sanz Mínguez, C. y Velasco Vázquez, J. 2003: Pintia. Un oppidum en los confines orientales de la región vaccea. Investigaciones Arqueológicas Vacceas, Romanas y Visigodas (1999-2003). Universidad de Valladolid. Valladolid.

Taracena, B. 1947: Adquisiciones del Museo Arqueológico Nacional 1940-1945. Madrid.

Torija López, A. y Baquedano Beltrán, I. 2007: «Las tesserae de la colección Cerralbo. Viejas conocidas, nuevas perspectivas». Paleohispanica 7: 269-336.

Tovar, A. 1948: «El bronce de Luzaga y las téseras de hospitalidad latinas y celtibéricas». Emerita 16: 7591.

Untermann, J. 1997: Monumenta Linguarum Hispanicarum IV. Die tartesischen, keltiberischen und lusitanschen Inschriften. Wiesbaden.

Vega, R.; Regino, R. y Van den Eynde, E. 1986: El oppidum de Celada Marlantes. Un poblado cántabro sin romanizar. Memoria de la excavación depositada en la Consejería de Cultura, Turismo y Deporte del Gobierno de Cantabria. 